\section{In Response to Deutchman et al}

\section{TO THE EDITOR:}

The United States faces an increasing shortage of primary care physicians, which community-based medical schools aim to overcome by increasing the primary care physician supply. ${ }^{1}$ The timely study by Deutchman and colleagues reveals the extent to which training of primary care physicians at allopathic medical schools may be overestimated, ${ }^{2}$ reporting that only $22 \%$ of graduates from a sample of 14 medical schools entered primary care practice. While this study was not designed to statistically compare the output of primary care physicians among schools or regions, the number of graduates entering primary care fields is frequently compared between schools to analyze their relative contribution to the primary care workforce. ${ }^{3}$ Such relative comparisons and rankings are useful for identifying schools that emphasize primary care training, but absolute benchmarks are needed for schools to know how many primary care physicians they must train to overcome the increasing shortage.

By 2023, the projected shortage of primary care physicians is between 21,400 and 55,200 nationally. ${ }^{4}$ However, this shortage varies significantly by state and is increasing much faster in some states than others. ${ }^{5}$ Based on the Health
Resources and Services Administration's projections spanning 2013-2025, ${ }^{5}$ we calculated the annualized increase in the primary care physician shortage for states represented in Deutchman et al's study. We then compared it to the annualized number of primary care physicians produced by each school (Table 1). Eight of 13 schools identified by name were located in states where the primary care physician shortage was increasing at a rate of 9-88 physicians/year. By comparison, each of these eight schools graduated 15-50 physicians per year who would go on to practice primary care. As an example of the gap between school-specific primary care physician training and the statewide rate of change in the physician shortage, the Brody School of Medicine (BSOM) at East Carolina University graduated an average of 71 physicians/year of whom 22 entered primary care practice, while the shortage of primary care physicians in North Carolina (where BSOM is one of four allopathic medical schools) grew by 42 per year.

For schools such as BSOM that have a mission to increase the supply of primary care physicians in their state, ${ }^{1}$ this comparison between alumni entering primary care and absolute benchmarks of primary care physician shortage reveals how far we must go to meet the demand for primary care physicians. Even if all BSOM graduates

Table 1: Number of Medical School Graduates Entering Primary Care Practice per Year, Compared to Annual Change of the Primary Care Physician Shortage in Each State

\begin{tabular}{|c|c|c|c|c|}
\hline \multirow[b]{2}{*}{ School } & \multirow[b]{2}{*}{ State } & \multicolumn{2}{|c|}{ Graduates per Year } & \multirow{2}{*}{$\begin{array}{l}\text { Annual Increase of } \\
\text { Primary Care Physician } \\
\text { Shortage in the State }\end{array}$} \\
\hline & & Total & $\begin{array}{c}\text { In Primary Care } \\
\text { Practice }\end{array}$ & \\
\hline University of Alabama & $\mathrm{AL}$ & 155 & 33 & 28 \\
\hline Case Western University & $\mathrm{OH}$ & 160 & 18 & 55 \\
\hline University of Colorado & $\mathrm{CO}$ & 150 & 28 & N/A \\
\hline Dartmouth & $\mathrm{NH}$ & 64 & 9 & N/A \\
\hline East Carolina & $\mathrm{NC}$ & 71 & 22 & 42 \\
\hline University of Illinois & $\mathrm{IL}$ & 344 & 50 & 50 \\
\hline University of Minnesota & $\mathrm{MN}$ & 217 & 72 & N/A \\
\hline University of Missouri & $\mathrm{MO}$ & 82 & 20 & 53 \\
\hline University of Nevada, Reno & $\mathrm{NV}$ & 56 & 15 & 9 \\
\hline University of North Carolina & $\mathrm{NC}$ & 157 & 49 & 42 \\
\hline Oregon Health \& Sciences University & OR & 108 & 25 & N/A \\
\hline University of South Florida & FL & 110 & 19 & 88 \\
\hline University of Washington & WA & 227 & 45 & N/A \\
\hline
\end{tabular}

a Data from Deutchman et al. ${ }^{2}$

${ }^{\mathrm{b}}$ Data from Health Resources and Services Administration, ${ }^{3}$ shown as physicians/year.

N/A, not applicable (state does not have a shortage of primary care physicians). 
entered primary care, it would not be sufficient to close the gap in the state. With other states facing similar challenges, multiple approaches may be required to meet the demand in states and regions where the primary care physician shortage is greatest. Approaches include incorporating community recommendations in the admissions process, increasing enrollment at primary carefocused schools, focusing on underrepresented student populations, or increasing production of primary care physicians at large research-oriented schools. Medical education leaders, health care professionals, and policy makers should look at statewide and regional strategies to increase numbers of primary care physicians, building upon the localized successes of individual schools. doi: 10.22454/FamMed.2021.646000

Dmitry Tumin, PhD

Jhojana L. Infante Linares, MS

Shawn A. Moore, EdD

Kendall M. Campbell, MD

Brody School of Medicine, East Carolina University

Greenville, NC

\section{References}

1. Campbell KM, Infante Linares Л, Tumin D, Faison K, Heath MN. The role of North Carolina medical schools in producing primary care physicians for the state. J Prim Care Community Health. 2020;11:2150132720924263. doi:10.1177/2150132720924263

2. Deutchman M, Macaluso F, Chao J, et al. Contributions of US medical schools to primary care (2003-2014): determining and predicting who really goes into primary care. Fam Med. 2020;52(7):483-490. doi:10.22454/FamMed.2020.785068

3. Beachler B, Jabbarpour Y, Kamerow DB, Wilkinson E, Levin Z, Bazemore A. New Allopathic Medical Schools Train Fewer Family Physicians Than Older Ones. J Am Board Fam Med. 2019;32(5):653-654. doi:10.3122/jabfm.2019.05.190105

4. Association of American Medical Colleges. The Complexities of Physician Supply and Demand: Projections From 2018 to 2033. https://www.aamc.org/system/files/2020-06/stratcomm-aamcphysician-workforce-projections-june-2020.pdf. Published June 2020. Accessed August 27, 2020.

5. Health Resources and Services Administration. State-level projections of supply and demand for primary care practitioners: 2013-2025. Rockville, MD: US Department of Health and Human Services; 2016.

\section{Shifting Priorities in Medical School}

\section{TO THE EDITOR:}

It was interesting to read the Deutchman et al study regarding the shortage of primary care physicians, significantly linked to a low rate of medical students matching into primary care residency positions in the United States. ${ }^{1}$ The COVID-19 pandemic shifted medical student priorities from board exams to family and self-care, so this is likely to have had an impact. ${ }^{2}$ Medical students are notorious for their hard work ethic and competitiveness, which ultimately brings with it a high level of mental health illness. The highly academic nature of the course, and the constant reminder of professionalism and fitness to practice have contributed to many medical students not seeking valuable mental health support. ${ }^{3}$

I have some suggestions based on surveys of health workers during the pandemic. The major factors highlighted for distress were the loss of loved ones, the isolation from not being able to visit friends or family, and the fear of spreading the disease. ${ }^{4}$ There has already been widespread discussion about the inevitability of future pandemics. These are possibly why medical students who had initially been aiming for emergency or acute medicine might be leaning towards a specialty that allows working from home and not having to socially distance, such as family medicine or general practice. In the United Kingdom, there has been a mass shift to video and telephone consultations as a result of the pandemic, and general practitioners have found their workload more manageable and less stressful, being able to work from home and without putting themselves and families at risk. ${ }^{5}$ Although a larger proportion of family physicians in the United States work in nursing homes and family care practices, reduced anxiety levels for the more competitive subjects combined with a more family-oriented point of view is likely to have a significant impact on primary care career choices made by medical students. Furthermore, previous research has shown that students primarily decide their specialty based on being able to explore areas of interest, work experience, and letters of recommendation. ${ }^{2}$ Perhaps during this time, they will have ended up with a more community-based portfolio, and they will shift their sights to primary care.

doi: 10.22454/FamMed.2021.556283

\section{Heather Mulrenan}

GKT School of Medical Education, King's College

London, United Kingdom

\section{References}

1. Deutchman M, Macaluso F, Chao J, et al. Contributions of US medical schools to primary care (2003-2014): determining and predicting who really goes into primary care. Fam Med. 2020;52(7):483-490. doi:10.22454/FamMed.2020.785068

2. Byrnes YM, Civantos AM, Go BC, McWilliams TL, Rajasekaran K. Effect of the COVID-19 pandemic on medical student career perceptions: a national survey study. Med Educ Online. 2020;25(1):1798088. doi:10.1080/10872981.2020.1798088

3. Bergmann C, Muth T, Loerbroks A. Medical students' perceptions of stress due to academic studies and its interrelationships with other domains of life: a qualitative study. Med Educ Online. 2019;24(1):1603526. doi:10.1080/10872981.2019.1603526

4. Mason DJ, Friese CR. Protecting health care workers against COVID-19 - and being prepared for future pandemics. JAMA Health Forum. 2020;1(3):e200353-e200353. doi:10.1001/jamahealthforum. 2020.0353

5. Thornton J. COVID-19: how coronavirus will change the face of general practice forever. BMJ. 2020;368:m1279. doi:10.1136/bmj. m1279 


\section{In Response to "Assessing Food Insecurity in Medical Students"}

\section{TO THE EDITOR:}

I applaud Flynn and colleagues for identifying an underdiscussed topic in their article titled "Assessing Food Insecurity in Medical Students." While there is growing literature, awareness, and interest in global food insecurity, rarely is the lens turned inward. Medical students represent a vulnerable population given their low income and rising cost of medical education (the median debt at graduation increased $\$ 142,000$ in 25 years even after adjustment for inflation). ${ }^{2}$ Interestingly, the researchers found that the prevalence of food insecurity at the Warren Alpert Medical School of Brown University to be similar to the general population (11.8\% vs $11.1 \%)$. Especially with the COVID-19 pandemic and its ensuing financial stressors, it's important to identify underlying causes for food insecurity in medical students.

First, it should be noted that the prevalence of food insecurity of those with a college education or higher is $5 \% .{ }^{3}$ Compared to this, medical students have more than double the expected rate. Despite going through rigorous undergraduate education, many medical students are not employed as they complete graduate school and instead continue to accrue debt. Of course, medical students can expect a salary much higher than most college graduates as attending physicians. However, this takes several years and, in the meantime, the burden of food insecurity is not to be underestimated. Food insecurity has well-studied, long-term detriments to both physical and mental health as well as academic outcomes. ${ }^{4,5}$ This impacts quality of medical training, wellness, and burnout and adds financial pressure to pursue some specialties over others. Even if food insecurity may be transient in medical students, its effects are not.

Secondly, the most commonly reported reason for food insecurity in the studied population was being unable to get to a store that sold the food that they wanted (33.96\%). The authors astutely pointed out that the school was situated in a food desert, defined as no supermarket with nutritious foods within 0.8 to $1.6 \mathrm{~km} .{ }^{6}$ However, literature shows that living less than $1.6 \mathrm{~km}$ from a supermarket with nutritious food was not associated with increased self-reported food security. One study in Pittsburgh, Pennsylvania found that while the average distance to a supermarket was $2.6 \mathrm{~km}$, the average respondent traveled $6.0 \mathrm{~km} .{ }^{7}$ United States Department of Agriculture (USDA) data shows that $64 \%$ of people bypassed the closest supermarket for a primary food source of greater distance. ${ }^{8} \mathrm{~A}$ common reason reported was low prices. Even if there were a nearby supermarket, access to affordable food may not be provided.

Additionally, the USDA data and similar studies found an association between food insecurity and having a personal automobile. ${ }^{9}$ Anecdotally, many medical students do not have access to a personal automobile for various reasons including cost and relocation. A combination of needing lower food prices and lack of a personal automobile is a dangerous combination for medical students.

Food insecurity is a significant barrier to health equity, and medical students are particularly vulnerable. Food insecurity has decreased in the last decade to match levels before the 2007 Great Recession. However, with the economic implications of the COVID-19 pandemic looming on the horizon, it is crucial that causes of food insecurity in medical students are identified so that medical schools can support and protect the future of our frontline forces.

doi: 10.22454/FamMed.2021.820941

Yufei Ge

University of Pittsburgh Medical Center-St Margaret

Pittsburg, PA

\section{References}

1. Flynn MM, Monteiro K, George P, Tunkel AR. Assessing food insecurity in medical students. Fam Med. 2020;52(7):512-513. doi:10.22454/FamMed.2020.722238

2. Pisaniello MS, Asahina AT, Bacchi S, et al. Effect of medical student debt on mental health, academic performance and specialty choice: a systematic review. BMJ Open. 2019;9(7):e029980. doi:10.1136/bmjopen-2019-029980

3. US Department of Agriculture Economic Research Service. Food Security in the U.S. Washington, DC: USDA; 2-10. https://www. ers.usda.gov/topics/food-nutrition-assistance/food-security-in-theus/. Accessed August 9, 2020

4. Bruening M, Argo K, Payne-Sturges D, Laska MN. The struggle is real: a systematic review of food insecurity on postsecondary education campuses. J Acad Nutr Diet. 2017;117(11):1767-1791. doi:10.1016/j.jand.2017.05.022

5. El Zein A, Shelnutt KP, Colby S, et al. Prevalence and correlates of food insecurity among U.S. college students: a multi-institutional study. BMC Public Health. 2019;19(1):660. doi:10.1186/ s12889-019-6943-6

6. Rhone A. VPM, Dicken C, Williams R, Breneman V. Low-income and low-supermarket-access census tracts, 2010-2015. Washington, DC: USDA; 2017.

7. Dubowitz T, Zenk SN, Ghosh-Dastidar B, et al. Healthy food access for urban food desert residents: examination of the food environment, food purchasing practices, diet and BMI. Public Health Nutr. 2015;18(12):2220-2230. doi:10.1017/S1368980014002742

8. Wilde P, Steiner A, Ver Ploeg M. For low-income Americans, Living $\leq 1$ Mile $(\leq 1.6 \mathrm{~km})$ from the nearest supermarket is not associated with self-reported household food security. Curr Dev Nutr. 2017;1(11):e001446. doi:10.3945/cdn.117.001446

9. Tolzman C, Rooney B, Duquette RD, Rees K. Perceived barriers to accessing adequate nutrition among food insecure households within a food desert. WMJ. 2014;113(4):139-143. 